\title{
Prognostic impact of soluble intercellular adhesion molecule-1 in hepatocellular carcinoma
}

\author{
TATSUO SHIMURA ${ }^{1}$, MASAHIKO SHIBATA ${ }^{2}$, KENJI GONDA ${ }^{2}$, YASUHIDE KOFUNATO ${ }^{1}$, TERUHIDE ISHIGAME ${ }^{1}$, \\ RYO OKADA $^{1}$, NAOYA SATO ${ }^{1}$, TAKASHI KIMURA ${ }^{1}$, AKIRA KENJO $^{1}$ and SHIGERU MARUBASHI ${ }^{1}$ \\ Departments of ${ }^{1}$ Hepato-Biliary-Pancreatic and Transplant Surgery, and ${ }^{2}$ Gastrointestinal Tract Surgery, \\ Fukushima Medical University, Fukushima 960-1259, Japan
}

Received April 16, 2018; Accepted August 22, 2018

DOI: $10.3892 / \mathrm{ol} .2018 .9367$

\begin{abstract}
The identification of novel biomarkers for hepatocellular carcinoma (HCC) is of great importance in improving the outcome of patients with HCC. The present study aimed to determine the prognostic significance of the soluble intercellular adhesion molecule (sICAM)-1 in patients with HCC. The present study prospectively collected clinicopathological data from 36 patients with HCC who had undergone successful hepatectomy. An analysis using a receiver operating characteristic (ROC) curve was performed to determine the cut-off value for predicting prognosis. Overall survival (OS), recurrence-free survival (RFS) and potential prognostic factors were analyzed. The ROC curve analysis revealed a sICAM-1 cut-off value of $440 \mathrm{ng} / \mathrm{ml}$. HCC patients with sICAM-1 $\geq 440 \mathrm{ng} / \mathrm{ml}$ exhibited a poorer OS and RFS than those with sICAM-1 <440 ng/ml ( $\mathrm{P}=0.002)$. sICAM-1 $\geq 440 \mathrm{ng} / \mathrm{ml}$ (hazard ratio $=3.623 ; 95 \%$ confidence interval: $1.145-11.458$; $\mathrm{P}=0.028$ ) and Child $\mathrm{B}$ (hazard ratio $=1.514 ; 95 \%$ confidence interval: $1.066-2.150 ; \mathrm{P}=0.021)$ were independent prognostic factors for OS, and sICAM-1 $\geq 440 \mathrm{ng} / \mathrm{ml}$ was an independent prognostic factor for RFS (hazard ratio $=3.625$; $95 \%$ confidence interval: 1.233-10.659; $\mathrm{P}=0.019)$. Serum sICAM-1 may be a promising predictor for the overall and recurrence-free survival of patients with HCC.
\end{abstract}

\section{Introduction}

Hepatocellular carcinoma (HCC), which accounts for $70-85 \%$ of the primary liver cancers (1), is the fifth most common cancer and second most common cause of cancer death in men worldwide (2). In 2012 alone, an estimated 782,500 new liver

Correspondence to: Professor Tatsuo Shimura, Department of Hepato-Biliary-Pancreatic and Transplant Surgery, Fukushima Medical University, 1 Hikarigaoka, Fukushima 960-1259, Japan E-mail: tshimura@fmu.ac.jp

Key words: hepatocellular carcinoma, intercellular adhesion molecule-1, overall survival, recurrence-free survival, prognosis cancer cases were diagnosed, and there were approximately 745,500 deaths due to liver cancer (2). Newly-developed therapeutics using direct-acting antivirals are eradicating most HCVs (3). However, the prognosis of HCC remains poor owing to tumor invasiveness, intra- and extra-hepatic metastasis, multicentric carcinogenesis, and resistance to chemotherapy $(4,5)$. The identification of novel biomarkers for $\mathrm{HCC}$ is therefore of great importance in improving the outcome of patients with HCC.

Cellular adhesion molecules, interacting cellular communications, are divided into four groups according to their molecular structures: Cadherins, selectins, integrins, and an immunoglobulin superfamily (6). Intercellular adhesion molecule (ICAM)-1, a member of the immunoglobulin superfamily, is broadly expressed on the membrane of normal tissues, and is selectively expressed in human malignancies (7-10). ICAM-1 is the ligand for the $\beta 2$-integrins, lymphocyte function-associated antigen (LFA)-1, and Mac-1 (11,12). The expression of ICAM-1 is regulated by locally produced inflammatory cytokines such as IL-1 $\beta$, tumor necrosis factor $\alpha$, interleukin (IL)-6, and interferon- $\gamma(13,14)$. Interestingly, the soluble form of ICAM-1 (sICAM-1) has also been reported to have angiogenic activity (15).

To elucidate the mechanisms of tumor progression in $\mathrm{HCC}$, and to establish certain prognostic markers, we investigated the serum concentration of SICAM-1 and its relationships with inflammatory and nutritional parameters.

\section{Materials and methods}

Patients. Thirty-six patients with HCC were enrolled (30 men and six women; mean age, 70.5 years; range, 34 to 84 years) in a prospective setting. In addition, samples from 27 healthy volunteers (10 males and 17 females, mean age, 54.3 years; range 35 to 84 years) were used as controls. Blood samples were collected from the patients between February 2011 and August 2013, before initiation of treatment. Sera from patients were stored at $-80^{\circ} \mathrm{C}$ until use. All of the patients underwent curative-intent surgery at our department. Following surgery, each patient's final cancer stage was determined pathologically according to the 8th edition of the TNM classification system of malignant tumors published by the Union for International Cancer Control (16). Liver fibrosis stage was determined 
according to the METAVIR score (17). In addition, the Child-Pugh score and indocyanine green retention rate at $15 \mathrm{~min}$ (ICGR15) were examined to evaluate liver function. The study protocol was approved by the ethics committee of Fukushima Medical University, and written informed consent was obtained from all enrolled patients and healthy volunteers. Thus, it was designed and conducted in accordance with Good Clinical Practice Guidelines and the latest revision of the Declaration of Helsinki.

Measurements of parameters. The serum concentrations of IL-6, vascular endothelial growth factor, and sICAM-1 were measured using an enzyme-linked immunosorbent assay (ELISA; R\&D Systems, Minneapolis, MN, USA) according to the manufacturer's instructions. Each sample was used only once after thawing, and not all blood samples were of sufficient volume for all measurements. Patient nutritional status was determined by measuring the serum concentrations of total protein, albumin, retinol binding protein (RBP), transthyretin (TTR), and transferrin, as well as body mass index (BMI) at diagnosis. These parameters were measured at the Central Clinical Laboratory of Fukushima Medical University Hospital. As for the inflammatory parameters, C-reactive protein (CRP), white blood cell count, neutrophil and lymphocyte counts, and the neutrophil-to-lymphocyte ratio (NLR), were used.

Statistical analysis. Data are presented as frequencies or percentages for categorical variables and mean \pm standard error for continuous variables, unless otherwise indicated. For categorical clinical variables, differences between the groups were evaluated using Fisher's exact test. The differences in mean values between the groups were analyzed using the Mann-Whitney $U$ test. A receiver operating characteristic (ROC) curve was used to evaluate the usefulness of the examined parameters as a prognostic factor, and associations between two variables were quantified using Spearman's rank correlation coefficient. The mean observation period was 68.5 months (median: 68.7, range: 45.3-83.9), and the final assessment of disease status was made on December 28, 2017. Overall survival (OS) and recurrence-free survival (RFS) were calculated using the Kaplan-Meier method, and differences between the groups were assessed by using the log-rank test. Factors found to be significant in the univariate analysis were subjected to multivariate analysis using a Cox proportional hazard model to identify independent predictors of prognosis. A two-sided P-value of $<0.05$ was considered statistically significant. All statistical calculations were performed using SPSS $^{\circledR}$ version 24 (IBM Japan, Tokyo, Japan).

\section{Results}

Analysis using an ROC curve. Patient characteristics are summarized in Table I. The sICAM-1 serum levels of the HCC patients (median: $438.9 \mathrm{ng} / \mathrm{ml}$, range: 101.1-994.0 ng/ml) were higher than those of the healthy volunteers (median: 207.6 ng/ml, range: 87.8-381.2 ng/ml) (P<0.001; Fig. 1A). In an analysis using a ROC curve (Fig. 1B), the serum sICAM-1 was evaluated as a useful biomarker to predict patient survival $(\mathrm{P}=0.022)$, and a sICAM-1 level of $440 \mathrm{ng} / \mathrm{dl}$ was determined as the cutoff value. At this cutoff value, sensitivity was 0.737 and specificity was 0.706 . Table II shows the patient characteristics according to serum sICAM-1 level. The incidence of ICGR $\geq 15$ was statistically higher in the patients with sICAM- $1 \geq 440$ than in those with sICAM-1 $<440(\mathrm{P}<0.001)$.

Association between SICAM-1 and other parameters. Fig. 2 shows the relationships between serum sICAM-1 levels and other parameters. The serum sICAM-1 levels exhibited statistically significant inverse correlations with TTR ( $\mathrm{r}=-0.379$, $\mathrm{P}=0.023$ ), and showed statistically significant correlations with ICGR15 ( $r=0.678, \mathrm{P}<0.001)$. However, the serum sICAM-1 showed no correlations with BMI.

Prognostic impact of SICAM-1. The evaluation of the prognostic factors was performed by dividing the patients into two groups for each parameter: Age ( $<75$ years vs. $\geq 75$ years), gender (male vs. female), serum sICAM-1 level (sICAM-1 <440 ng/ml vs. $\geq 440 \mathrm{ng} / \mathrm{ml}$ ), $\mathrm{T}$ factor (T1 vs. T2), Child-Pugh classification (A vs. B), intrahepatic metastasis (negative vs. positive), vascular invasion (negative vs. positive), and biliary invasion (negative vs. positive). As shown in Fig. 3, the patients with sICAM-1 $\geq 440 \mathrm{ng} / \mathrm{ml}$ showed poorer OS and RFS than those with sICAM-1 $<440 \mathrm{ng} / \mathrm{ml}(\mathrm{P}=0.002$ and $\mathrm{P}=0.002$, respectively).

Table III summarizes the analyses of a Cox proportional hazard model. With regard to OS, sICAM-1 $\geq 440 \mathrm{ng} / \mathrm{ml}$, T2, intrahepatic metastasis positive, vascular invasion positive, and biliary invasion positive showed statistical significance in the univariate analysis. sICAM-1 $\geq 440 \mathrm{ng} / \mathrm{ml}$ (hazard ratio: 3.623 , $95 \%$ confidence interval: $1.145-11.458, \mathrm{P}=0.028$ ) and Child $\mathrm{B}$ (hazard ratio: 1.514, 95\% confidence interval: 1.066-2.150, $\mathrm{P}=0.021$ ) were independent prognostic factors for OS in the multivariate analysis. With regard to RFS, sICAM-1 $\geq 440 \mathrm{ng} / \mathrm{ml}$, T2, intrahepatic metastasis positive, vascular invasion positive, and biliary invasion positive showed statistical significance in the univariate analysis. In the multivariate analysis, sICAM-1 $\geq 440 \mathrm{ng} / \mathrm{ml}$ was an independent prognostic factor for the RFS of HCC patients (hazard ratio: 3.625, 95\% confidence interval: 1.233-10.659, $\mathrm{P}=0.019)$.

\section{Discussion}

Immunohistochemically, ICAM-1 is expressed on hepatocytes in cancerous areas but not on hepatocytes in noncancerous areas (18). It has recently been reported that ICAM-1 was a marker of HCC stem cells, and increased numbers of $\mathrm{CD}^{-} \mathrm{ICAM}^{+}$tumor cells in blood samples of HCC patients correlated with worse clinical outcomes (19). On the other hand, circulating SICAM-1 has been reported to be elevated in the serum of patients with various malignancies (20-28). With regard to HCC, Shimizu et al reported that sICAM-1 $\geq 1,000 \mathrm{ng} / \mathrm{ml}$ was associated with poor prognosis in HCC patients who had been treated by transcatheter arterial chemoembolization (20), and Zhu et al reported that sICAM-1 $>684 \mathrm{ng} / \mathrm{ml}$ was an independent prognostic factor for OS and RFS in HCC patients who had undergone surgical treatment (21). Our results on the usefulness of sICAM-1 for predicting the survival of HCC patients confirmed their findings; however, our sICAM-1 cutoff threshold of $440 \mathrm{ng} / \mathrm{ml}$ was lower than those of the other two studies. With regard 
Table I. Patient demographics.

\begin{tabular}{|c|c|c|}
\hline Category & $\mathrm{N}$ & $(\%)$ \\
\hline \multicolumn{3}{|l|}{ Age } \\
\hline$<75$ & 24 & 66.7 \\
\hline$\geq 75$ & 12 & 33.3 \\
\hline \multicolumn{3}{|l|}{ Sex } \\
\hline Male & 30 & 83.3 \\
\hline Female & 6 & 16.7 \\
\hline \multicolumn{3}{|l|}{$\mathrm{T}$} \\
\hline T1a & 8 & 22.2 \\
\hline T1b & 16 & 44.4 \\
\hline $\mathrm{T} 2$ & 12 & 33.3 \\
\hline \multicolumn{3}{|l|}{$\mathrm{N}$} \\
\hline N0 & 33 & 91.7 \\
\hline N1 & 3 & 8.3 \\
\hline \multicolumn{3}{|l|}{ M } \\
\hline M0 & 36 & 100.0 \\
\hline M1 & 0 & 0.0 \\
\hline \multicolumn{3}{|l|}{ Stage } \\
\hline IA & 8 & 22.2 \\
\hline IB & 16 & 44.4 \\
\hline II & 10 & 27.8 \\
\hline III & 0 & 0.0 \\
\hline IVA & 2 & 5.6 \\
\hline \multicolumn{3}{|l|}{ Operation } \\
\hline Partial & 10 & 27.8 \\
\hline Segmentectomy & 5 & 13.9 \\
\hline Sectionectomy & 7 & 19.4 \\
\hline Lobectomy & 8 & 22.2 \\
\hline Extended lobectomy & 6 & 16.7 \\
\hline \multicolumn{3}{|c|}{$\begin{array}{l}\mathrm{n}=36 \text {. Partial, partial hepatectomy; TNM, tumor-node-metastasis. } \\
\mathrm{T}, \mathrm{N} \text { and } \mathrm{M} \text { factors and TNM stage were determined pathologically } \\
\text { according to the } 8 \text { th edition of the TNM classification system of } \\
\text { malignant tumors published by the Union for International Cancer } \\
\text { Control. }\end{array}$} \\
\hline
\end{tabular}

to the meanings of higher sICAM-1, it has been reported that sICAM-1 inhibits ICAM-1/LFA-1-mediated cell-to-cell interaction, resulting in tumor cells escaping from cell-mediated immune surveillance $(27,29)$. This escape theory seems possible, considering that a high amount of circulating sICAM-1 was an independent prognostic factor for the RFS in patients with HCC in the present study. Since the source of increased circulating level of the serum SICAM-1 has yet to be elucidated, further investigation will be needed.

We revealed the relationships of serum SICAM-1 levels with the TTR levels and ICGR15. TTR, also known as prealbumin, has a relatively short half-life (approximately two days) and is the earliest laboratory indicator of malnutrition status, as it contains a high percentage of essential amino acids (30). Systemic chronic inflammation has been reported to induce angiogenesis and malnutrition. Thus, higher sICAM-1 might
Table II. Patient demographics according to sICAM-1 level.

\begin{tabular}{|c|c|c|c|}
\hline Characteristics & $\begin{array}{c}\text { sICAM-1 }<440 \\
(n=18)\end{array}$ & $\begin{array}{c}\text { sICAM-1 } \geq 440 \\
(n=18)\end{array}$ & P-value \\
\hline Age & & & 1.000 \\
\hline$<75$ & 12 & 12 & \\
\hline$\geq 75$ & 6 & 6 & \\
\hline Sex & & & 0.658 \\
\hline Male & 14 & 16 & \\
\hline Female & 4 & 2 & \\
\hline $\mathrm{T}$ & & & 0.075 \\
\hline $\mathrm{T} 1$ & 15 & 9 & \\
\hline $\mathrm{T} 2$ & 3 & 9 & \\
\hline $\mathrm{N}$ & & & 0.229 \\
\hline No & 18 & 15 & \\
\hline N1 & 0 & 3 & \\
\hline Stage & & & 0.229 \\
\hline Stage I-III & 18 & 15 & \\
\hline Stage IV & 0 & 3 & \\
\hline Virus & & & 1.000 \\
\hline- & 7 & 8 & \\
\hline+ & 11 & 10 & \\
\hline ICGR 15 & & & $<0.001^{\mathrm{a}}$ \\
\hline$<15$ & 18 & 7 & \\
\hline$\geq 15$ & 0 & 11 & \\
\hline PT & & & 0.603 \\
\hline$\geq 70$ & 15 & 17 & \\
\hline$<70$ & 3 & 1 & \\
\hline Child-Pugh & & & 1.000 \\
\hline A & 17 & 16 & \\
\hline B & 1 & 2 & \\
\hline AFP & & & 0.479 \\
\hline$<10.0$ & 8 & 6 & \\
\hline$\geq 10.0$ & 7 & 10 & \\
\hline
\end{tabular}

Fibrosis score

0.691

$$
\text { F1-3 }
$$$$
\text { F4 }
$$$$
15
$$$$
5
$$

Intrahepatic metastasis

$\begin{array}{lrr}- & 17 & 8 \\ + & 1 & 10 \\ \text { Vascular invasion } & & \\ - & 16 & 13 \\ + & 2 & 5 \\ \text { Biliary invasion } & & \\ - & 15 & 9 \\ + & 3 & 9\end{array}$

${ }^{\mathrm{a}} \mathrm{P}<0.05$. sICAM-1, soluble form of intercellular adhesion molecule-1; virus, hepatitis B or C virus infection; ICGR15, the retention of indocyanine green after $15 \mathrm{~min}$; $\mathrm{T}$, tumor; $\mathrm{N}$, node; PT, prothrombin time; AFP, $\alpha$ fetoprotein. 

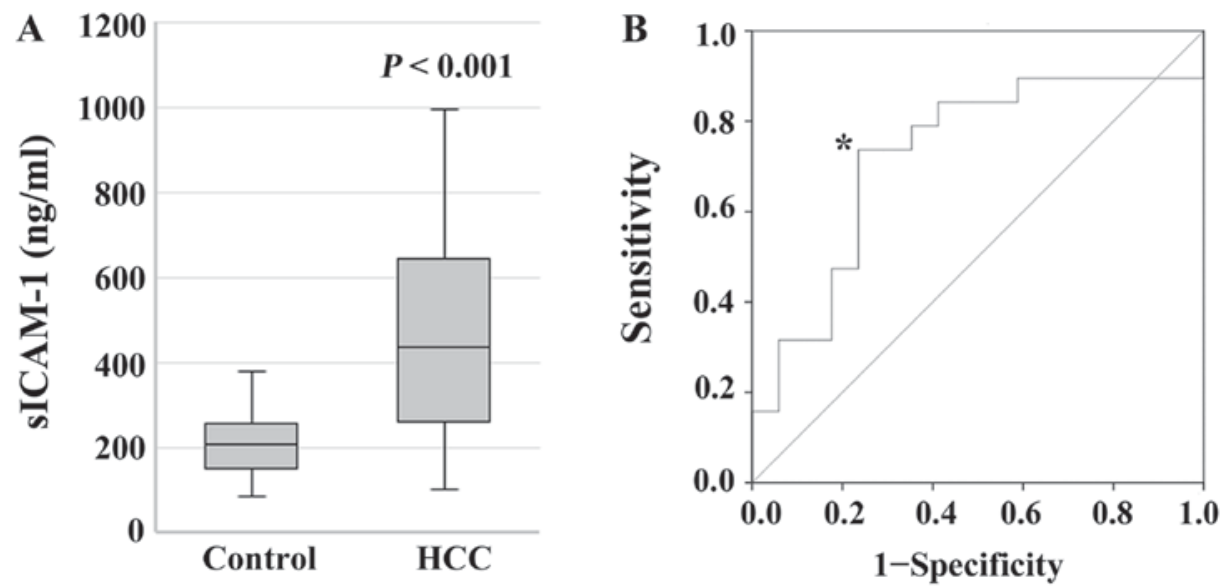

Figure 1. (A) The box-and-whisker plots of sICAM-1. The sICAM-1 serum levels of the patients with HCC (median, $438.9 \mathrm{ng} / \mathrm{ml}$; range, $101.1-994.0 \mathrm{ng} / \mathrm{ml}$ ) were higher than those of the healthy volunteers (median, $207.6 \mathrm{ng} / \mathrm{ml}$; range, 87.8-381.2 ng/ml; P<0.001). (B) Receiver operating characteristic curve for transthyretin. The calculated area under the curve was 0.724 . "The coordinate point when the cut-off threshold of the transthyretin was set to $440 \mathrm{ng} / \mathrm{ml}$. sICAM-1, soluble form of intercellular adhesion molecule 1; HCC, hepatocellular carcinoma.
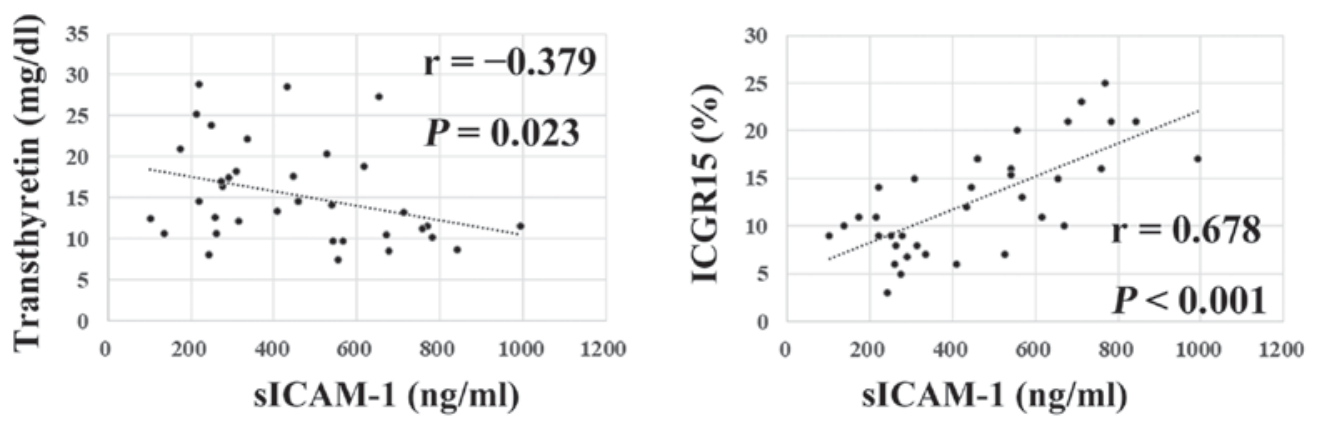

Figure 2. Association between sICAM-1 and other parameters. The sICAM-1 levels exhibited statistically significant inverse correlations with transthyretin $(\mathrm{r}=-0.379, \mathrm{P}=0.023)$, and exhibited statistically significant correlations with the indocyanine green retention rate at $15 \mathrm{~min}(\mathrm{ICGR} 15)(\mathrm{r}=0.678, \mathrm{P}<0.001)$ sICAM-1, soluble form of intercellular adhesion molecule 1.
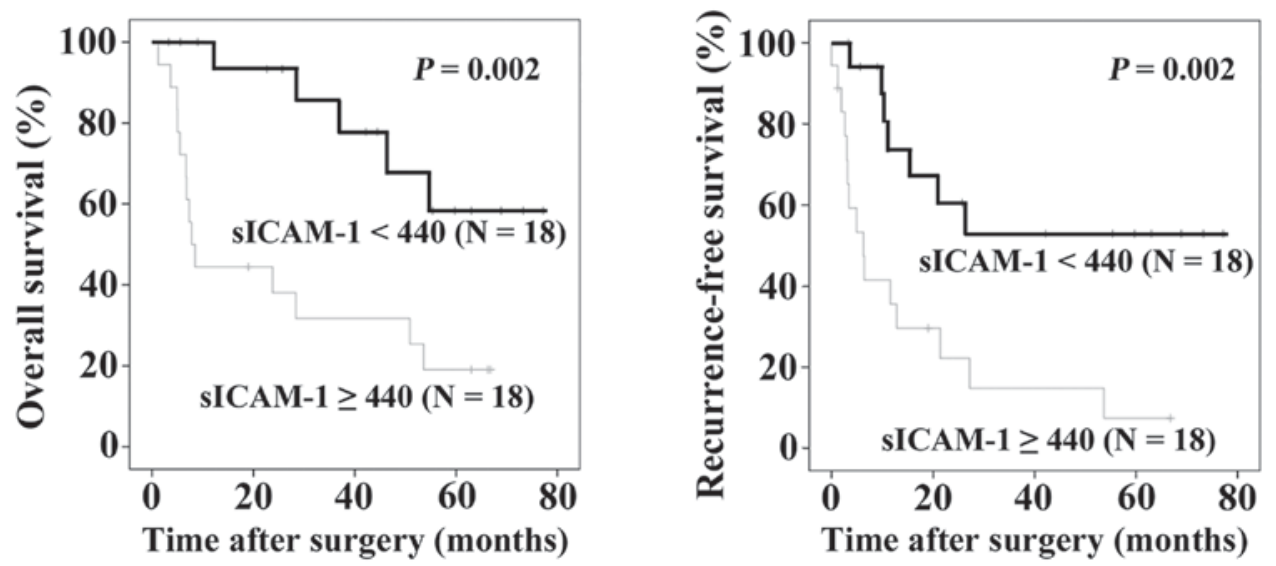

Figure 3. Association between serum sICAM-1 levels and overall and recurrence-free survival. The patients with sICAM-1 $\geq 440 \mathrm{ng} / \mathrm{ml}$ exhibited poorer overall and recurrence-free survival rates than those with sICAM- $1<440 \mathrm{ng} / \mathrm{ml}(\mathrm{P}=0.002$ and $\mathrm{P}=0.002$, respectively). sICAM-1, soluble form of intercellular adhesion molecule 1.

be one of the causes of lower serum TTR levels. The meaning of the correlation between sICAM-1 and ICGR15 remains unclear; however, angiogenesis in tumors may prolong the retention of indocyanine green.

There are some limitations to the current study. First is its small sample size. In addition, it is costly and troublesome to examine sICAM-1 in every HCC patient. However, further investigations are warranted whether higher serum sICAM-1 is due to HCC stem cells or circulating tumor cells expressing ICAM-1.

In conclusion, our analysis using a ROC curve revealed that the cutoff value of SICAM-1 for predicting the prognosis 
Table III. Cox proportional hazards model.

A, Overall survival

\begin{tabular}{|c|c|c|c|c|c|c|}
\hline \multirow[b]{2}{*}{ Variable } & \multicolumn{3}{|c|}{ Univariate analysis } & \multicolumn{3}{|c|}{ Multivariate analysis } \\
\hline & HR & $95 \% \mathrm{CI}$ & P-value & $\mathrm{HR}$ & $95 \% \mathrm{CI}$ & P-value \\
\hline Age $<75$ vs. $\geq 75$ & 1.092 & $0.383-3.116$ & 0.869 & & & \\
\hline Sex male vs. female & 0.622 & $0.144-2.696$ & 0.526 & & & \\
\hline sICAM-1 $<440 \mathrm{ng} / \mathrm{ml}$ vs. $\geq 440 \mathrm{ng} / \mathrm{ml}$ & 4.368 & $1.562-12.216$ & $0.005^{\mathrm{a}}$ & 3.623 & $1.145-11.458$ & $0.028^{\mathrm{a}}$ \\
\hline T T1 vs. T2 & 4.011 & $1.576-10.210$ & $0.004^{\mathrm{a}}$ & 0.782 & $0.148-4.116$ & 0.771 \\
\hline Child-Pugh A vs. B & 1.521 & $1.155-2.003$ & $0.003^{\mathrm{a}}$ & 1.514 & $1.066-2.150$ & $0.021^{\mathrm{a}}$ \\
\hline IM negative vs. positive & 3.847 & $1.079-13.719$ & $0.038^{\mathrm{a}}$ & 0.743 & $0.119-4.643$ & 0.750 \\
\hline V negative vs. positive & 4.063 & $1.397-11.816$ & $0.010^{\mathrm{a}}$ & 4.441 & $0.902-21.864$ & 0.067 \\
\hline B negative vs. positive & 2.113 & $1.087-4.108$ & $0.027^{\mathrm{a}}$ & 2.594 & $0.779-8.642$ & 0.121 \\
\hline
\end{tabular}

B, Recurrence-free survival

\begin{tabular}{|c|c|c|c|c|c|c|}
\hline \multirow[b]{2}{*}{ Variable } & \multicolumn{3}{|c|}{ Univariate analysis } & \multicolumn{3}{|c|}{ Multivariate analysis } \\
\hline & HR & $95 \% \mathrm{CI}$ & P-value & HR & $95 \% \mathrm{CI}$ & P-value \\
\hline Age $<75$ vs. $\geq 75$ & 1.031 & $0.416-2.553$ & 0.947 & & & \\
\hline Sex male vs. female & 0.952 & $0.321-2.823$ & 0.930 & & & \\
\hline sICAM-1 $<440 \mathrm{ng} / \mathrm{ml}$ vs. $\geq 440 \mathrm{ng} / \mathrm{ml}$ & 3.776 & $1.528-9.331$ & $0.004^{\mathrm{a}}$ & 3.625 & $1.233-10.659$ & $0.019^{\mathrm{a}}$ \\
\hline T T1 vs. T2 & 6.119 & $2.389-16.085$ & $<0.001^{\mathrm{a}}$ & 2.434 & $0.488-12.135$ & 0.278 \\
\hline Child-Pugh A vs. B & 1.371 & $1.087-1.728$ & $0.003^{\mathrm{a}}$ & 1.177 & $0.850-1.629$ & 0.328 \\
\hline IM negative vs. positive & 3.553 & $1.013-12.467$ & $0.048^{\mathrm{a}}$ & 1.088 & $0.166-7.120$ & 0.930 \\
\hline V negative vs. positive & 2.736 & $1.024-7.309$ & $0.045^{\mathrm{a}}$ & 1.142 & $0.234-5.575$ & 0.870 \\
\hline B negative vs. positive & 3.002 & $1.539-5.858$ & $0.001^{\mathrm{a}}$ & 2.808 & $0.906-8.706$ & 0.930 \\
\hline
\end{tabular}

${ }^{\mathrm{a}} \mathrm{P}<0.05$. HR, hazards ratio; CI, confidence interval; sICAM-1, soluble form of intercellular adhesion molecule 1; IM, intrahepatic metastasis; $\mathrm{T}, \mathrm{T}$ factor; $\mathrm{V}$, vascular invasion; $\mathrm{B}$, biliary invasion.

of the HCC patients was $440 \mathrm{ng} / \mathrm{ml}$. The serum sICAM-1 levels in the current study exhibited statistically significant inverse correlations with TTR, and showed statistically significant correlations with ICGR15. The patients with sICAM-1 $\geq 440 \mathrm{ng} / \mathrm{ml}$ showed poorer OS and RFS than those with sICAM-1 <440 ng/ml. Furthermore, sICAM-1 $\geq 440 \mathrm{ng} / \mathrm{ml}$ and Child $\mathrm{B}$ were independent prognostic factors for OS, and sICAM-1 $\geq 440 \mathrm{ng} / \mathrm{ml}$ was an independent prognostic factor for RFS in HCC patients.

\section{Acknowledgements}

Not applicable.

\section{Funding}

No funding was received.

\section{Availability of data and materials}

The analyzed data sets generated during the study are available from the corresponding author upon reasonable request.

\section{Authors' contributions}

TS and MS contributed to concept, design, and integrity of this study. YF, RO, TI, TK, AK and NS performed data acquisition, analysis, or data interpretation. TS and MS drafted the manuscript and critically revised it for important intellectual content.

\section{Ethics approval and consent to participate}

This retrospective study was carried out in accordance with the ethical standards of the institutional research committee and with the 1964 Helsinki declaration and its later amendments or ethical standards. Written informed consent was obtained from all enrolled patients. All patient data were treated in accordance with the local privacy regulations.

\section{Patient consent for publication}

Not applicable.

\section{Competing interests}

The authors declare that they have no competing interests. 


\section{References}

1. El-Serag HB: Hepatocellular carcinoma. N Engl J Med 365: 1118-1127, 2011

2. Torre LA, Bray F, Siegel RL, Ferlay J, Lortet-Tieulent J and Jemal A: Global cancer statistics, 2012. CA Cancer J Clin 65: 87-108, 2015.

3. Kohli A, Shaffer A, Sherman A and Kottilil S: Treatment of hepatitis C: A systematic review. JAMA 312: 631-640, 2014.

4. Lim KC, Chow PK, Allen JC, Siddiqui FJ, Chan ES and Tan SB: Systematic review of outcomes of liver resection for early hepatocellular carcinoma within the Milan criteria. Br J Surg 99: 1622-1629, 2012.

5. Thelen A, Benckert C, Tautenhahn HM, Hau HM, Bartels M, Linnemann J, Bertolini J, Moche M, Wittekind C and Jonas S: Liver resection for hepatocellular carcinoma in patients without cirrhosis. Br J Surg 100: 130-137, 2013.

6. Springer TA: Adhesion receptors of the immune system. Nature 346: 425-434, 1990 .

7. Smith ME and Thomas JA: Cellular expression of lymphocyte function associated antigens and the intercellular adhesion molecule-1 in normal tissue. J Clin Pathol 43: 893-900, 1990.

8. Maio M, Pinto A, Carbone A, Zagonel V, Gloghini A, Marotta G, Cirillo D, Colombatti A, Ferrara F, Del Vecchio L, et al: Differential expression of CD54/intercellular adhesion molecule-1 in myeloid leukemias and in lymphoproliferative disorders. Blood 76: 783-790, 1990.

9. Natali P, Nicotra MR, Cavaliere R, Bigotti A, Romano G, Temponi $\mathrm{M}$ and Ferrone S: Differential expression of intercellular adhesion molecule 1 in primary and metastatic melanoma lesions. Cancer Res 50: 1271-1278, 1990.

10. Vánky F, Wang P, Patarroyo M and Klein E: Expression of the adhesion molecule ICAM-1 and major histocompatibility complex class I antigens on human tumor cells is required for their interaction with autologous lymphocytes in vitro. Cancer Immunol Immunother 31: 19-27, 1990.

11. Diamond MS, Staunton DE, de Fougerolles AR, Stacker SA, Garcia-Aguilar J, Hibbs ML and Springer TA: ICAM-1 (CD54): A counter-receptor for Mac-1 (CD11b/CD18). J Cell Biol 111: 3129-3139, 1990

12. Carlos TM and Harlan JM: Leukocyte-endothelial adhesion molecules. Blood 84: 2068-2101, 1994.

13. Sallusto F and Lanzavecchia A: Efficient presentation of soluble antigen by cultured human dendritic cells is maintained by granulocyte/macrophage colony-stimulating factor plus interleukin 4 and downregulated by tumor necrosis factor alpha. J Exp Med 179: 1109-1118, 1994.

14. Shen J, Devery JM and King NJ: Adherence status regulates the primary cellular activation responses to the flavivirus West Nile. Immunology 84: 254-264, 1995.

15. Gho YS, Kleinman HK and Sosne G: Angiogenic activity of human soluble intercellular adhesion molecule-1. Cancer Res 59: 5128-5132, 1999.

16. Wittekind C: Hepatobiliary section. In: TNM Classification of Malignant Tumours, 8th edition. Brierley JD, Gospodarowicz MK and Wittekind C (eds.) Wiley, West Sussex, pp80-82, 2017.
17. Bedossa P and Poynard T: An algorithm for the grading of activity in chronic hepatitis C. The METAVIR Cooperative Study Group. Hepatology 24: 289-293, 1996.

18. Momosaki S, Yano H, Ogasawara S, Higaki K, Hisaka T and Kojiro M: Expression of intercellular adhesion molecule 1 in human hepatocellular carcinoma. Hepatology 22: 1708-1713, 1995.

19. Liu S, Li N, Yu X, Xiao X, Cheng K, Hu J, Wang J, Zhang D, Cheng S and Liu S: Expression of intercellular adhesion molecule 1 by hepatocellular carcinoma stem cells and circulating tumor cells. Gastroenterology 144: 1031-1041, 2013.

20. Shimizu Y, Minemura M, Tsukishiro T, Kashii Y, Miyamoto M, Nishimori H, Higuchi K and Watanabe A: Serum concentration of intercellular adhesion molecule-1 in patients with hepatocellular carcinoma is a marker of the disease progression and prognosis. Hepatology 22: 525-531, 1995.

21. Zhu PP, Yuan SG, Liao Y, Qin LL and Liao WJ: High level of intercellular adhesion molecule-1 affects prognosis of patients with hepatocellular carcinoma. World J Gastroenterol 21: 7254-7263, 2015.

22. Harning R, Mainolfi E, Bystryn JC, Henn M, Merluzzi VJ and Rothlein R: Serum levels of circulating intercellular adhesion molecule 1 in human malignant melanoma. Cancer Res 51: 5003-5005, 1991

23. Grothey A, Heistermann P, Philippou S and Voigtmann R: Serum levels of soluble intercellular adhesion molecule-1 (ICAM-1, CD54) in patients with non-small-cell lung cancer: Correlation with histological expression of ICAM-1 and tumour stage. Br J Cancer 77: 801-807, 1998.

24. Zhang GJ and Adachi I: Serum levels of soluble intercellular adhesion molecule-1 and E-selectin in metastatic breast carcinoma: Correlations with clinicopathological features and prognosis. Int J Oncol 14: 71-77, 1999.

25. Kitagawa T, Matsumoto $\mathrm{K}$ and Iriyama K: Serum cell adhesion molecules in patients with colorectal cancer. Surg Today 28: 262-267, 1998.

26. Benekli M, Güllü IH, Tekuzman G, Savaş MC, Hayran M, Hasçelik G and Firat D: Circulating intercellular adhesion molecule-1 and E-selectin levels in gastric cancer. Br J Cancer 78: 267-271, 1998.

27. Becker JC, Termeer C, Schmidt RE and Bröcker EB: Soluble intercellular adhesion molecule-1 inhibits MHC-restricted specific T cell/tumor interaction. J Immunol 151: 7224-7232, 1993.

28. Shimura T, Shibata M, Gonda K, Kofunato Y, Okada R, Ishigame T, Kimura T, Kenjo A, Marubashi S, Kono K and Takenoshita S: Clinical significance of soluble intercellular adhesion molecule-1 and interleukin-6 in patients with extrahepatic cholangiocarcinoma. J Invest Surg: Sep 19, 2017 (Epub ahead of print).

29. Altomonte M, Colizzi F, Esposito G and Maio M: Circulating intercellular adhesion molecule 1 as a marker of disease progression in cutaneous melanoma. N Engl J Med 327: 959, 1992.

30. Spiekerman AM: Nutritional assessment (protein nutriture). Anal Chem 67: 429R-436R, 1995. 